employs is arguably one of its shortcomings. The task of critical reasoning can be conceived more broadly as that of forming well-founded beliefs. One might also take issue with some of Mutti's definitions of logical concepts. For example, it is a requirement on a deductive argument that its premises be such that we must accept them (p. 96), and in a discussion of implication within conditionals, logical truth is taken to be equivalent to a version of Fregean analyticity because it is defined in term of a notion of implication whereby one assertion implies another if the former contains all of the same information as the latter (pp. 17-22). These definitions are flagged as partially stipulative, but they are non-standard.

Although some of the topics could be covered in more depth, Making $U p$ Your Mind presents a clear narrative that will no doubt succeed in helping students to engage with the subject matter. Because all of the answers to the numbered exercises are in the back of the book, the text is probably most useful as a secondary workbook for students; however, the type of argumentconstruction exercises covered in Chapter Seven are worth including in any course on critical reasoning.

Lisa Warenski Advisors Program, Honors College The City University of New York 365 Fifth Avenue New York, NY 10016

\title{
Walking the Tightrope of Reason: The Precarious Life of a Rational Animal by Robert Fogelin
}

Oxford: Oxford University Press, 2003. 224pp. Hardcover: ISBN 0-19516026-6, US\$22.00. Paperback: ISBN 0-19-517753-1, US\$12.95

\section{Reviewed by Daniel H. Cohen}

In a survey of the history of the field, Ralph Johnson notes that Robert Fogelin was among the first to use the phrase "informal logic" in its current sense. While Fogelin's most recent book, Walking the Tightrope of Reason: The Precarious Life of a Rational Animal, does not directly address questions from the discourses of informal logic, argumentation theory or critical thinking, it beautifully exhibits the tools of argument analysis. It is a splendid example of philosophical argumentation and deserves the attention of workers in those fields. Fogelin has a sophisticated understanding of what argumentation is all about and he is admirably adept in practice. When it comes to philosophical argumentation in particular, he has a deep understanding of how it can go wrong. And, of more importance, he has definite ideas on how it can be made right. 
As Johnson also noted, the term "informal logic" had an interesting prior use in Gilbert Ryle's Dilemmas to refer to conceptual analysis more generally. The connection is apposite because there is a lot in Walking the Tightrope of Reason to remind one of Dilemmas. They are similar in terms of their scopes, the tone and style of their arguments, their philosophical goals, and, in some measure, in their analyses and proposals as well. Both books began as a series of public lectures delivered by a distinguished philosopher addressing the structure and nature of philosophical problems broadly, yet neither loses sight of the trees for the forest. Both are sophisticated, deeply conversant with philosophical traditions, and deceptively subtle. From the torrent of philosophical arguments, they distill interesting patterns to philosophical arguments. In both cases, what they find can be of great value as vehicles for thinking about specific philosophical problems as well as for thinking about the nature of philosophical problems more generally. And, like Ryle, Fogelin brings what might be called, for lack of a better phrase, a mature philosophical perspective to bear.

When Ryle looked at philosophical problems, he saw dilemmas, boundary disputes between different fields using distinct but overlapping vocabularies. Philosophers, because they occupy the spaces between the specialized disciplines, are uniquely situated to help sort things out by identifying category mistakes, clarifying methodological issues, disentangling complex questions, and finally divvying up the pieces. Even if Ryle may have overreached himself in trying to fit all philosophical problems into that format, we can still appreciate the applicability of his conceptual contributions for many controversies.

Fogelin is only somewhat more modest in his claims. Like Ryle, Fogelin is embarked on a project that is very ambitious in the end. A general framework for thinking about a very large class of philosophical problems is sketched out. Three different kinds of responses to those problems that are available within that framework are noted. Finally, the deformations that can result from the initial impulses behind each of those three sorts of responses are identified. Symptoms typically involve inconsistency, illusion or doubt, which, if left untreated, can develop into relativisms, dogmatisms, or skepticisms of various stripes. The diagnosis is critical and the prognosis for philosophy is dire, so in his best Wittgensteinian desk-side manner, Dr. Fogelin prescribes a purgative therapy for our troubled conceptual system. There are deeply embedded "shared misunderstandings" that have to be rooted out.

From the beginning, traces of the book's provenance as a series of Romanell lectures are visible. Those lectures were intended for a general literate audience, and that intent combined with Fogelin's own literate style yields a whole that is written with elegance and grace. The opening chapter in particular is charmingly accessible but, perhaps as a result, tends toward the superficial. It seems to have little or nothing to offer of significant interest to anyone who has thought about these problems before, but that is deceptive. Anyone resting content with that sample of the book would be missing out. The opening chapter never reaches closure on its title question, "Why Obey the Laws of 
Logic," but it does set the stage for the deft, largely Humean and later Wittgensteinian analyses that follow. We are reminded again why Hume is so important and why Wittgenstein's philosophy has had such tremendous appeal. They are in the hands of an adept here.

As for the question of obeying logic's laws, the first point to state is the obvious one: they are not that kind of law. They are more like the descriptive laws of physics than the prescriptive laws of society. But, quite properly, they do play a regulative role in theory formation. Fogelin presents the argument over the law of noncontradiction (LNC) as "a paradigm of a radical disagreement driven by a shared underlying misunderstanding" (p.19).

That shared misunderstanding is expressible as a conditional: If the law of noncontradiction is correct, then change is impossible. The discussion that follows illustrates the old chestnut that one philosopher's modus ponens is another's modus tollens. In the example at hand, Parmenides and Heraclitus are taken as representative of the extremes, united by the shared commitment to an absolutist conception of truth that includes transcendence, permanence, and immutability and excludes appearance, immanence and change. The important thing to note is the structure of the debate: it is centered on a powerful conditional connecting two different areas of thought. This is the template that Fogelin finds applicable to other large philosophical differences. He cites as further examples Dostoyevsky"s "If there is no God, then everything is pointless" and C. I. Lewis" "If anything is to be probable, then something must be certain." It is easy enough to find other examples near at hand to further buttress Fogelin's claim:

If the language of truth and falsity is the language of sense, then Ethics, Metaphysics, and Theology make no sense.

If there can be ethical knowledge, then there can be a science of ethics. If the meaning of the word "pain" in the sentence "I have a pain" is its reference to the pain that I have, then no one else could understand what I mean by that sentence.

If I do not know that I am not dreaming, then I do not know that I am standing here. (From G. E. Moore, Certainty)

It really is a common pattern in philosophical disputes. To point it out is already to perform a valuable service by providing philosophers another way to think about their arguments.

Fogelin offers a truth-table analysis to disentangle the debate over the law of noncontradiction. The analysis concludes that there is no connection between the LNC and change - but it also shows that while the LNC is indeed true, it is a completely empty truth. He does admit that his initial logico-linguistic analysis begs the question because it assumes that truth-tables can allow only one value per entry, and that $\mathrm{T}$ and $\mathrm{F}$ are the only choices. Unfortunately, he loses sight of that and the remainder of his argument in the first chapter targets a Straw Man. "If we reject the law of noncontradiction - that is, really reject it, not just pretend to reject it-it is hard to think of any reason for not engaging in anything-goes interpretations" (p. 37). 
Even setting aside the (also question-begging) assumption that a contradiction implies anything, Fogelin is wrong: it is not particularly hard to think of reasons for stopping well short of anything-goes interpretations. If the LNC as a general principle is expressed, with quantification over propositions, as:

(p) $\sim(\mathrm{p} \& \sim \mathrm{p}) \quad$ (All propositions are not both true and false) then its denial is surely NOT:

(p)(p \& $\sim \mathrm{p}) \quad$ (All propositions are both true and false).

The latter is required for the anything-goes conclusion. The denial that corresponds to the negation of the LNC is

\section{$\sim(p) \sim(p \& \sim p)$ (Not all propositions are not both true and false)}

or

(p) $(\sim \mathrm{p} \& \mathrm{p}) \quad$ (Some propositions are both true and false).

Either the second or third versions could be part of a radical claim about truth (e.g., an extreme post-modern rejection of truth per se). However, the third might instead be a claim about the restricted applicability of LNC in some contexts (e.g., quantum physics or theological discourse). Or, it could be the modest (and eminently reasonable) suggestion that the language of classical two-valued logic is inadequate for modeling the full richness of ordinary language and the subtle nuances of critical argumentation. For some analyses, logical conjunction and classical negation are indeed rather blunt tools.

Fogelin understands that defending the LNC as unassailably analytic empties it of any content, and thus that the remarks in the first chapter defending the LNC largely miss the point of what its critics are after - as well as what is really at stake. It is with this recognition that the discussion comes into its own. The possibility that inconsistencies, contradictions, and paradoxes might be ineliminable parts of certain structures is admitted, and strategies for coping with them, rather than solutions that close the door, are outlined. Much of the discussion is centered around a very clever thought experiment that imagines a popular but complex board game called "Ludwig," perhaps something like chess. It is a game, we suppose, whose rules evolved over a long time, but they have been settled for a long time, and now there are regular tournaments and shelves of books on strategy. Suppose now, that after centuries of games, an inconsistency in its rules is discovered. The rules contradict themselves concerning a peculiar and unexpected position that arises in a game. That position had never arisen before because it can only result from an extraordinary amount of strategic incompetence or indifference on the part of the players, but once it has arisen, there is a move that Ludwig's rules both prohibit and mandate. How is the situation to be described? How are we to respond to it? Does that invalidate all the games in the past? What if the rules cannot be easily fixed? Anyone not already familiar with this example or examples of its type will be very tempted to appropriate it as a pedagogical vehicle for discussing linguistic paradoxes, moral dilemmas, Wittgenstein's philosophy, or even, as Fogelin intends here, philosophy itself. I heartily commend such appropriation. 
Fogelin takes the lessons he learns from this Gedankenexperiment and applies them to the question of standards in aesthetics. Are there objective standards? Well, the objectivists and the subjectivists can agree on this much: if there are no objective standards, then it seems it must be entirely a matter of subjective taste. But beware those conditionals! We may be embracing intuitive principles that, in the event, may lead to conceptual insolubilia. Fogelin appeals to his other philosophical hero and goes Humean. Just as we cannot in practice really be skeptics, so too we cannot really refrain from making aesthetic judgments. Beauty may be in the eye of the beholder, but so are red and blue, sweet and sour, and all the other secondary qualities. Neither dyers nor chefs need be discomfited one whit by the philosophical discovery that the relevant qualities of the materials they manipulate are secondary. Much the same can be said on behalf of the art critic. One can acknowledge the general sense of humanity on aesthetic matters without hypostatizing them into transcendental rules. Education and training in the arts can be distinguished from indoctrination and regimentation. The contributions made by technique, creativity, and traditions in the arts can be appreciated with discrimination. Together, these can help us find our way out of this particular philosophical flybottle.

Aesthetic judgments may be far from the logical, dialectical, and rhetorical judgments we want to make about arguments, but there are insights in Fogelin's discussion of aesthetics that can be profitably transferred to argumentation theory. We may say that there is no disputing taste and also that the laws of logic are beyond dispute, but we are wrong on both counts. We can and we do argue in both areas without a second thought. We should have second thoughts, though, because it is without them that our lives as rational animals become precarious. Relativism about arguments that is rooted in rhetoric may be easier to avoid than relativism rooted in subjectivism about aesthetic matters. If so, that probably just means we need to be correspondingly more wary of the dogmatism of deductivism in argumentation than we do about dogmatic aesthetics. The skeptical trap, however, is avoided in the same way: a successful analysis of argumentation has to situate arguments in our lives, just as aesthetics cannot strand apart from the judgments we in fact make and the traditions in which we do live. That project, however, belongs to another book-one that Fogelin would be well qualified to write and one that, if he were to write it, I would be very happy to read.

Daniel H. Cohen Department of Philosophy Colby College Waterville, Maine 04901 